\title{
Communication
}

\section{pH-Dependent Release of Insulin from Layer-by-Layer-Deposited Polyelectrolyte Microcapsules}

\section{Kentaro Yoshida $^{1, *}$, Tetsuya Ono ${ }^{1}$, Yoshitomo Kashiwagi ${ }^{1}$, Shigehiro Takahashi ${ }^{2}$, Katsuhiko Sato ${ }^{2}$ and Jun-ichi Anzai ${ }^{2}$}

1 School of Pharmaceutical Sciences, Ohu University, 31-1 Misumido, Tomita-machi, Koriyama, Fukushima 963-8611, Japan; E-Mails: t-ono@pha.ohu-u.ac.jp (T.O.);

y-kashiwagi@pha.ohu-u.ac.jp (Y.K.)

2 Graduate School of Pharmaceutical Sciences, Tohoku University, Aramaki, Aoba-ku, Sendai 980-8578, Japan; E-Mails: t-shigehiro@m.tohoku.ac.jp (S.T.); satok@m.tohoku.ac.jp (K.S.); junanzai@mail.pharm.tohoku.ac.jp (J.A.)

* Author to whom correspondence should be addressed; E-Mail: k-yoshida@pha.ohu-u.ac.jp; Tel.: +81-24-932-8931; Fax: +81-24-933-7372.

Academic Editor: Cyrille Boyer

Received: 7 May 2015 / Accepted: 3 July 2015 / Published: 13 July 2015

\begin{abstract}
Insulin-containing microcapsules were prepared by a layer-by-layer (LbL) deposition of poly(allylamine hydrochloride) (PAH) and polyanions, such as poly(styrenesulfonate) (PSS), poly(vinyl sulfate) (PVS), and dextran sulfate (DS) on insulin-containing calcium carbonate $\left(\mathrm{CaCO}_{3}\right)$ microparticles. The $\mathrm{CaCO}_{3}$ core was dissolved in diluted $\mathrm{HCl}$ solution to obtain insulin-containing hollow microcapsules. The microcapsules were characterized by scanning electron microscope (SEM) and atomic force microscope (AFM) images and $\zeta$-potential. The release of insulin from the microcapsules was faster at $\mathrm{pH} 9.0$ and 7.4 than in acidic solutions due to the different charge density of PAH. In addition, insulin release was suppressed when the microcapsules were constructed using PAH with a lower molecular weight, probably owing to a thicker shell of the microcapsules. The results suggested a potential use of the insulin-containing microcapsules for developing insulin delivery systems.
\end{abstract}

Keywords: insulin; controlled release; polyelectrolyte microcapsule; layer-by-layer film; drug delivery 


\section{Introduction}

Polyelectrolyte layer-by-layer (LbL) films can be prepared by an alternate and repeated deposition of polymeric materials on a solid surface through electrostatic interactions [1,2], hydrogen binding [3,4], host-guest complexation [5,6], and biological affinity [7]. A recent review has summarized biocompatible LbL films for smart materials [8]. This diversity of methods has led to a variety of materials, including synthetic polymers [9], nanoparticles [10], proteins [11], cells [12], and polysaccharides [13], being used for constructing LbL films. LbL films have been used in sensors [14], separation and purification membranes [15], stimuli-sensitive devices [16,17], and drug delivery systems [18,19]. Hollow microcapsules have also been constructed by coating the surface of microspheres with LbL films followed by dissolution of core material [20-24]. A merit of LbL film-based microcapsules is that whole working process can be carried out in water under mild conditions (i.e., neutral $\mathrm{pH}$ at room temperature). Therefore, microcapsules containing unstable compounds, such as proteins and genes, can be successfully prepared [25-27].

In this context, we reported that insulin can be built into LbL films by an alternate deposition of polymers and insulin to enable $\mathrm{pH}$-controlled release of insulin [28-30]. Biodegradable microspheres were also used as support for depositing insulin LbL films [31]. Insulin was released from the LbL films and microspheres at neutral $\mathrm{pH}$ while the release was suppressed at acidic $\mathrm{pH}$, suggesting a possible use of them for developing oral administrations of insulin.

We report here the preparation of insulin-containing LbL microcapsules and their $\mathrm{pH}$-dependent insulin release. The LbL microcapsules were prepared by coating insulin-containing $\mathrm{CaCO}_{3}$ particles with LbL films, followed by dissolution of $\mathrm{CaCO}_{3}$ core in acidic solution.

\section{Experimental Section}

\subsection{Materials}

Insulin (Human, recombinant) was purchased from Wako Pure Chemical Industry (Osaka, Japan). Poly(allylamine hydrochloride) (PAH, molecular weight $\left(M_{\mathrm{W}}\right): 1000,15,000$, and 70,000) were acquired from Nittobo Co. (Tokyo, Japan) and used without further purification. Poly(styrene sulfate) (PSS, $M_{\mathrm{w}}$ : 500,000), poly(vinyl sulfonate) (PVS, $\left.M_{\mathrm{w}}: 240,000\right)$, and dextran sulfate (DS, $M_{\mathrm{w}}$ : 25,000) were obtained from Scientific Polymer Product, Inc. (New York, NY, USA), Nacalai Tesque Co. (Kyoto, Japan), and Tokyo Kasei Co. (Tokyo, Japan), respectively. Tetramethylrhodamine-5-isothiocyanate (TRITC) was obtained from Sigma-Aldrich Co. (St. Louis, MO, USA) and used for preparing TRITC-labeled insulin (TRITC-insulin). TRITC-insulin was synthesized by the coupling reaction of TRITC and insulin according to the reported procedure [32].

\subsection{Preparation of LbL Microcapsules}

Ten milliliters of $0.2 \mathrm{M} \mathrm{CaCl}_{2}$ (Wako Pure Chemical Industry, Osaka, Japan) solution containing $5 \mathrm{mg}$ of insulin or TRITC-insulin was mixed with $10 \mathrm{~mL}$ of $0.2 \mathrm{M}\left(\mathrm{NH}_{3}\right)_{2} \mathrm{CO}_{3}$ (Wako Pure Chemical Industry, Osaka, Japan) solution containing $40 \mathrm{mg}$ PSS under stirring. The mixture was stirred for $30 \mathrm{~min}$, and the precipitated particles were collected by centrifugation and washed with distilled water. The surface of $\mathrm{CaCO}_{3}$ particles was coated with $\mathrm{LbL}$ film by immersing the $\mathrm{CaCO}_{3}$ particles alternately 
in $0.5 \mathrm{mg} \mathrm{mL}^{-1} \mathrm{PAH}$ and $0.5 \mathrm{mg} \mathrm{mL}^{-1}$ polyanion (PSS, PVS, and DS) in $10 \mathrm{mM}$ Tris-HCl buffer (Nacalai Tesque Inc., Kyoto, Japan) containing $150 \mathrm{mM} \mathrm{NaCl}$ (Wako Pure Chemical Industry, Osaka, Japan) (pH 7.4) for $15 \mathrm{~min}$. After each deposition, the $\mathrm{CaCO}_{3}$ particles were collected by centrifugation and rinsed in the working buffer for $5 \mathrm{~min}$. Then, $\mathrm{LbL}$ film-coated particles were dispersed in excess amount of $0.1 \mathrm{M} \mathrm{HCl}$ solution to dissolve the $\mathrm{CaCO}_{3}$ core, and the resulting hollow microcapsules were thoroughly rinsed in $10 \mathrm{mM}$ acetate buffer ( $\mathrm{pH}$ 3.0) containing $150 \mathrm{mM} \mathrm{NaCl}$. The whole process was carried out at room temperature. The amounts of TRITC-insulin loaded in the microcapsules were found to be $0.23 \pm 0.01,0.13 \pm 0.03$, and $0.20 \pm 0.08 \mathrm{mg}$ in $1 \mathrm{mg}$ of lyophilized (PAH/PSS) 5 , (PAH/PVS) 5 and $(\mathrm{PAH} / \mathrm{DS})_{5}$ microcapsules, respectively.

\subsection{AFM and SEM Images of $\mathrm{CaCO}_{3}$ Particles and Microcapsules}

A suspension of $\mathrm{CaCO}_{3}$ particles with and without film coating or $\mathrm{LbL}$ microcapsules was dispersed on a glass slide, which had been cleaned using chromic acid/sulfuric acid mixture, and then dried in a desiccator for scanning electron microscope (SEM) (S-3200N, Hitachi Co., Tokyo, Japan) and atomic force microscope (AFM) (SPM-9600, Shimadzu, Japan) observation. The SEM samples were sputtered with platinum. AFM images were taken in contact mode using a microcantilever (OMCL-TR800PSA-1 (Olympus, Tokyo, Japan) at room temperature in air.

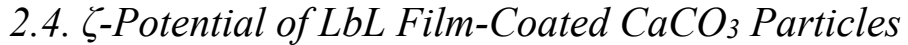

The $\zeta$-potential of $\mathrm{LbL}$ film-coated $\mathrm{CaCO}_{3}$ particles was recorded using a $\zeta$-potential analyzer (Zeecom/ZC-2000, Microtec Co., Funabashi, Japan) at pH 7.0.

\subsection{Evaluation of Insulin Release from Microcapsules}

The release of insulin was evaluated in $10 \mathrm{mM}$ acetate buffer at $\mathrm{pH} 1.4-6.0$ or in $10 \mathrm{mM}$ Tris buffer at $\mathrm{pH}$ 7.0-9.0 (all buffer solutions contained $150 \mathrm{mM} \mathrm{NaCl}$ ). TRITC-insulin-containing microcapsules were suspended in the buffer solutions under gentle stirring. The dispersion was centrifuged occasionally and the fluorescence intensity of the supernatant was recorded at $530 \mathrm{~nm}$ (excitation: $488 \mathrm{~nm}$ ) to estimate the concentration of TRITC-insulin released from the microcapsules.

\section{Results and Discussion}

\subsection{Preparation of Insulin-Containing Microcapsules}

Insulin-containing microcapsules were prepared by depositing LbL films on the surface of insulin-loaded $\mathrm{CaCO}_{3}$ particles followed by dissolution of $\mathrm{CaCO}_{3}$ core, as illustrated in Figure 1. In this protocol, insulin is encapsulated in the cavity in the form of insulin-PSS aggregates created through electrostatic interactions because the microcapsules were prepared by using $\mathrm{CaCO}_{3}$ particles containing PSS and insulin. The preparation of microcapsules was evaluated by measuring $\zeta$-potential of $\mathrm{CaCO}_{3}$ particles coated with LbL film, as well as SEM and AFM images. 


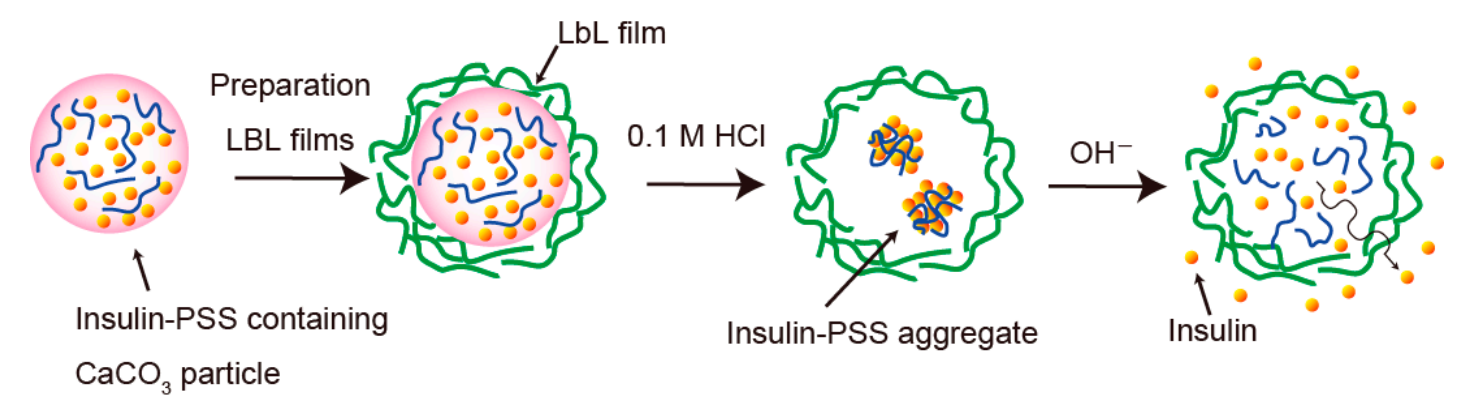

Figure 1. A schematic illustration of the preparation of insulin-containing microcapsule.

Figure 2 shows plots of typical $\zeta$-potential of $\mathrm{CaCO}_{3}$ particles coated with $\mathrm{PAH} / \mathrm{PSS}, \mathrm{PAH} / \mathrm{PAA}$, and $\mathrm{PAH} / \mathrm{DS}$ films. Positive values were obtained when the outermost layer was $\mathrm{PAH}$, while the $\zeta$-potentials were negative when the outermost was PSS, PAA, or DS. These results show that electric charges on the surface of the $\mathrm{CaCO}_{3}$ particles coated with $\mathrm{LbL}$ films alternated between positive to negative according to the type of the outermost material, which demonstrates successful deposition of LbL films on the $\mathrm{CaCO}_{3}$ particles.

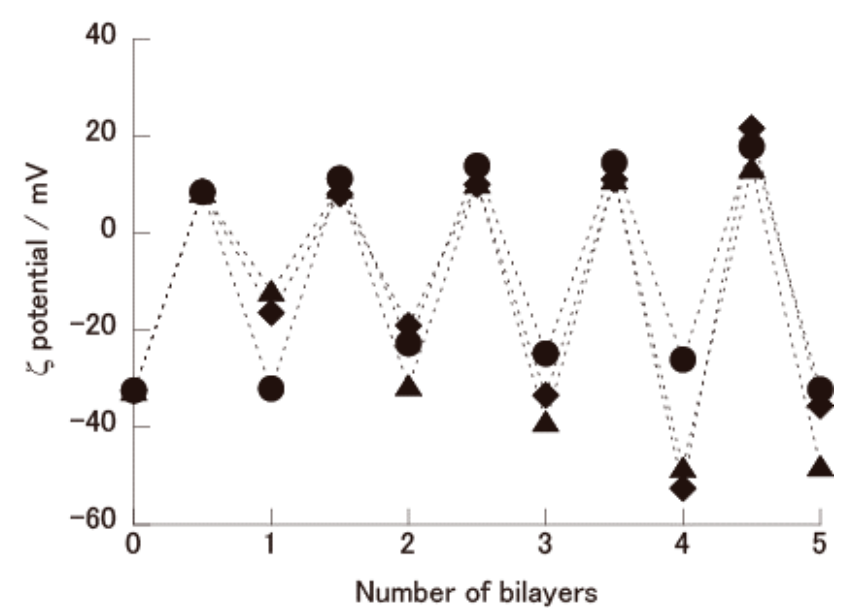

Figure 2. Typical $\zeta$-potential of $\mathrm{CaCO}_{3}$ particles coated with $\mathrm{PAH} / \mathrm{PSS}(\bullet), \mathrm{PAH} / \mathrm{PVS}(\boldsymbol{\Delta})$, and $\mathrm{PAH} / \mathrm{DS}(\diamond)$ films. The outermost is PSS, PVS, or DS when the number of bilayers is an integer.

Figure 3 shows SEM images of $\mathrm{CaCO}_{3}$ microparticles, (PAH/PSS) 5 film-coated $\mathrm{CaCO}_{3}$ particles, and (PAH/PSS) 5 hollow microcapsules. Spherical $\mathrm{CaCO}_{3}$ particles 3-6 $\mu \mathrm{m}$ in diameter are clearly seen in Figure 3A. Figure 3B is a SEM image of (PAH/PSS) 5 film-coated $\mathrm{CaCO}_{3}$ particles. The (PAH/PSS) film-coated $\mathrm{CaCO}_{3}$ particles exhibited a slightly smooth surface compared to uncoated $\mathrm{CaCO}_{3}$ particles, suggesting a successful deposition of (PAH/PSS) 5 film on $\mathrm{CaCO}_{3}$ particles. The (PAH/PSS) 5 film-coated $\mathrm{CaCO}_{3}$ particles were dispersed in $0.1 \mathrm{M} \mathrm{HCl}$ solution to dissolve the $\mathrm{CaCO}_{3}$ core and rinsed in a buffer solution of $\mathrm{pH}$ 3.0. Figure 3C shows a SEM image of dried hollow (PAH/PSS) 5 microcapsules thus prepared. The dried microcapsules are spreading onto the substrate with typical folds. Similar SEM images for dried LbL microcapsules have often been reported [33,34]. 

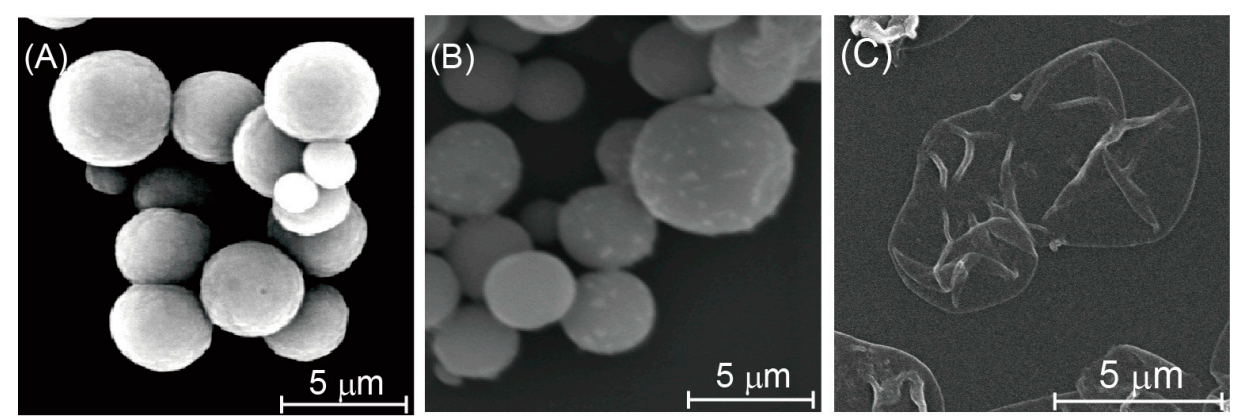

Figure 3. $\mathrm{SEM}$ images of $\mathrm{CaCO}_{3}$ particles containing insulin and PSS (A), (PAH-PSS) film-coated $\mathrm{CaCO}_{3}$ particles (B); and dried (PAH/PSS) 5 microcapsules (C).

To further verify the microcapsule preparation, AFM images of dried (PAH/PVS) 5 microcapsules with and without insulin loading were recorded (Figure 4). The vertical sectional profile of the empty microcapsule and the insulin-loaded ones were different from each other. The shell thickness of the empty microcapsule was estimated to be approximately $30 \mathrm{~nm}$ at its thinnest portion (Figure 4A). Interestingly, on the other hand, the dried insulin-containing microcapsule was thicker due to insulin-PSS aggregates loaded in the capsule (Figure 4B). Thus, the SEM and AFM images ensure successful preparation of (PAH/PSS $)_{5}$ microcapsules containing insulin.
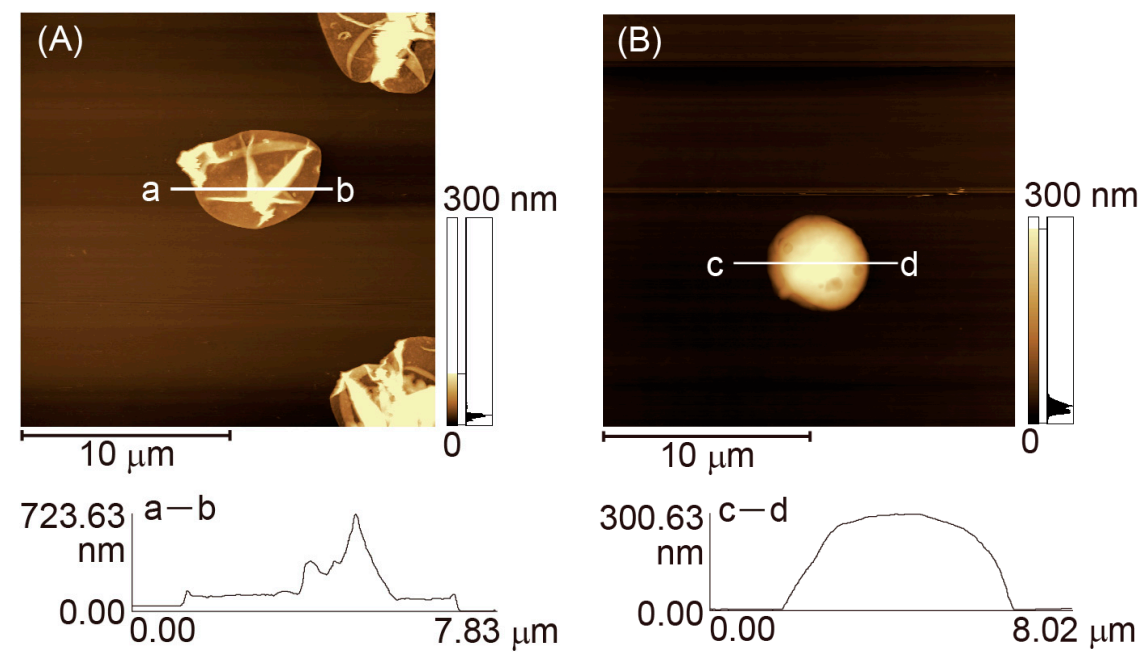

Figure 4. AFM images of dried (PAH/PVS)5 microcapsule without insulin loaded (A) and microcapsules containing insulin-PSS aggregates $(\mathbf{B})$. The sectional profiles $\mathrm{a}-\mathrm{b}$ and $\mathrm{c}-\mathrm{d}$ show thickness of the dried microcapsules.

\section{2. pH-Dependent Release of Insulin from Microcapsules}

The release of insulin from the LbL microcapsules was studied by means of fluorescence spectroscopy using microcapsules containing TRITC-insulin. The time course of TRITC-insulin release from (PAH/PSS)5, (PAH/PVS $)_{5}$ and (PAH/DS)5 microcapsules is shown in Figure 5. The release of TRITC-insulin from the microcapsules significantly depended on $\mathrm{pH}$ of the medium. The TRITC-insulin release was suppressed in acidic media ( $\mathrm{pH}$ 1.4-3.0) for all microcapsules tested. The formation of TRITC-insulin-PSS aggregates in the microcapsules may be responsible for the suppressed release in the acidic media. TRITC-insulin and the anionic PSS should form aggregates through electrostatic interactions at pH 5.0 
or lower because insulin contains a net positive charge (the isoelectric point of insulin is 5.4 [35]). In fact, we have previously found that insulin binds to anionic polymers to form aggregates in acidic media $[28,29]$. It is plausible that the high-molecular-weight aggregates could not be transported across the shell of the microcapsules.
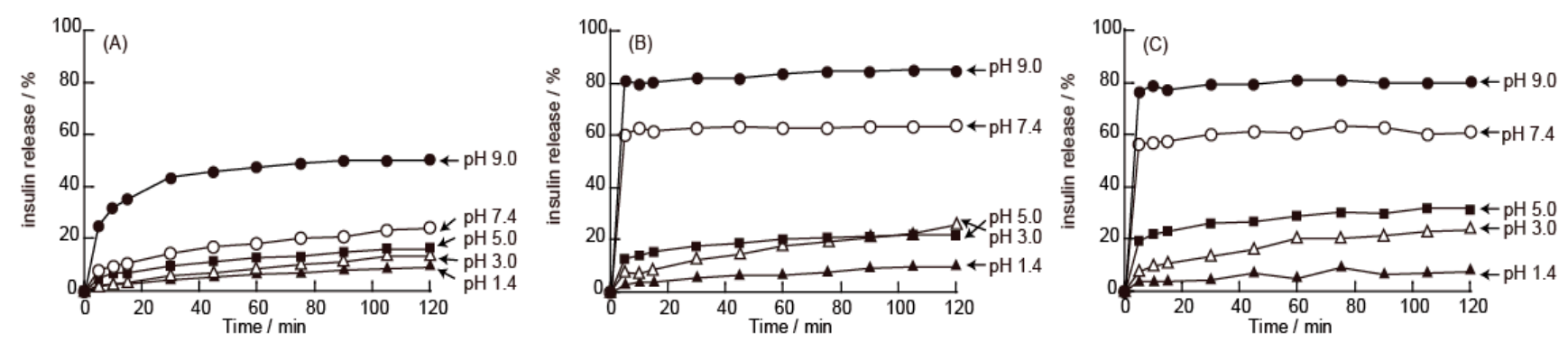

Figure 5. TRITC-Insulin release from (PAH/PSS) 5 (A); (PAH/PVS $)_{5}(\mathbf{B})$ and $(\mathrm{PAH} / \mathrm{DS})_{5}$ (C) microcapsules in the media with different $\mathrm{pH}$. The solution $\mathrm{pH}$ was $\mathrm{pH} 1.4(\mathbf{\Delta}), \mathrm{pH} 3.0(\Delta)$, pH 5.0 (匹), pH 7.4 (०), and pH $9.0(\bullet)$.

In contrast, TRITC-insulin released rapidly from (PAH/PVS) 5 and (PAH/DS) 5 microcapsules at pH 7.4 and 9.0, while the release was slower for (PAH/PSS) 5 microcapsules. The enhanced release at neutral and basic pHs results from dissociation of TRITC-insulin-PSS aggregates in the neutral and basic media, in which insulin is negatively charged. It is reasonable that TRITC-insulin molecules can be transported out of the capsules more effectively than the aggregates. The release of TRITC-insulin was higher in $\mathrm{pH} 9.0$ medium than in $\mathrm{pH} 7.4$ solution. It is likely that, at $\mathrm{pH} 7.4$, a part of TRITC-insulin was electrostatically adsorbed into the PAH layer at the inner surface of the microcapsule shell. The electrostatic interactions between TRITC-insulin and PAH at pH 9.0 may be weaker than those at pH 7.4 owing to reduced positive charges of PAH. It should be noted here that Bäumler and coworkers reported that LbL microcapsules consisting of PAH and PSS exhibited no $\mathrm{pH}$ dependent permeability for macromolecules such as human albumin [36]. In addition, Mauser and coworkers reported that PAH-poly(methacrylic acid) microcapsules exhibited $\mathrm{pH}$-independent swelling in the $\mathrm{pH}$ range from 2.7 to 11.5 [37]. These findings strongly suggest that $\mathrm{pH}$-dependent release of TRITC-insulin from the microcapsules should be attributed mainly to $\mathrm{pH}$-dependent formation/decomposition of TRITC-insulin/PSS aggregates in the microcapsules, as illustrated in Figure 1. A similar $\mathrm{pH}$-dependent insulin release from LbL microcapsules composed of alginic acid and chitosan has been reported by Ye and coworkers [38]. The amount of TRITC-insulin released from (PAH/PSS)5 microcapsules was smaller than those released from (PAH/PVS)5 and (PAH/DS)5 microcapsules. This may originate from different porosity of the microcapsule shell, i.e., the aromatic ring in PSS may result in tighter binding to PAH in the microcapsule shell.

Figure 6 shows release profiles of TRITC-insulin from (PAH/PSS)5 microcapsules constructed with PAHs of different molecular weights. The release of TRITC-insulin was accelerated at $\mathrm{pH} 7.4$ as compared to that in acidic media irrespective of molecular weights of PAH. Interestingly, TRITC-insulin release from the microcapsules constructed from low-molecular-weight PAH ( $M \mathrm{w}$ : 1000) was slightly slower than those from the microcapsules composed of higher-molecular-weight PAHs. These results show that permeability or porosity of the microcapsule shell depends on the molecular weight of PAH 
used. In this context, it has been reported that LbL films fabricated using low-molecular-weight polymers are thicker than those constructed using higher-molecular-weight ones [39,40]. The (PAH/PSS)5 microcapsules constructed with PAH of lower molecular weight may consist of thicker shell, resulting in slower release of TRITC-insulin.
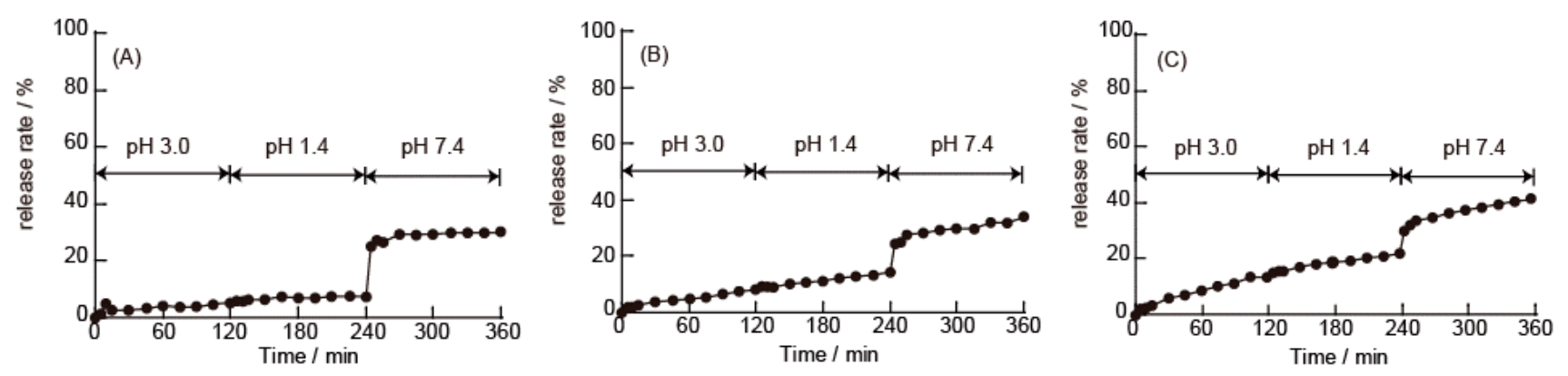

Figure 6. The effect of molecular weight of PAH on the release of TRITC-Insulin from (PAH/PSS) 5 microcapsules. The average molecular weight of PAH used was 1000 (A), $15,000(\mathbf{B})$, and 70,000 (C).

\section{Conclusions}

We have prepared polyelectrolyte microcapsules containing insulin by coating insulin-containing $\mathrm{CaCO}_{3}$ particles with $\mathrm{LbL}$ films followed by $\mathrm{CaCO}_{3}$ dissolution. The release of insulin from the prepared microcapsules was accelerated at $\mathrm{pH} 7.4$ and 9.0 while suppressed at $\mathrm{pH} 1.4-5.0$, as a result of formation of insulin-PSS aggregates in the microcapsules. In addition, insulin release from (PAH-PSS) 5 microcapsules constructed using PAH of lower molecular weight was slower than that from high-molecular-weight PAH-based microcapsules. Insulin-containing polyelectrolyte microcapsules prepared in this study may be useful in the development of insulin delivery systems.

\section{Acknowledgments}

This work was partially supported by the Japan Society for the Promotion of Science Grants-in-Aid for Scientific Research (grant numbers 26860111 and 24390006). The authors thank Toshinori Ito (Ohu University) for his help in manuscript preparation.

\section{Author Contributions}

All authors were involved in the experimental works and the manuscript was prepared by Kentaro Yoshida and Jun-ichi Anzai.

\section{Conflicts of Interest}

The authors declare no conflict of interest. 


\section{References}

1. Decher, G.; Hong, J.D. Building up ultrathin multilayer films by a self-assembly process: II. Consecutive adsorption of anionic and cationic bipolar amphiphiles and polyelectrolytes on charged surfaces. Ber. Bunsenges. Phys. Chem. 1991, 95, 1430-1434.

2. Decher, G. Fussy nanoassemblies: Toward layered polymeric multicomposites. Science 1997, 277, 1232-1237.

3. Pavlukhina, S.; Sukhishvili, S. Polymer assemblies for controlled delivery of bioactive molecules from surfaces. Adv. Drug Deliv. Rev. 2011, 63, 822-836.

4. Tomita, S.; Sato, K.; Anzai, J. Layer-by-layer assembled thin films composed of carboxyl-terminated poly(amidoamine) dendrimers as a pH-sensitive nano-device. J. Colloid Interface Sci. 2008, 326, $35-40$.

5. Suzuki, I.; Egawa, Y.; Mizukawa, Y.; Hoshi, T.; Anzai, J. Construction of positively-charged layered assemblies assisted by cyclodextrin complexation. Chem. Commun. 2002, 2, 164-165.

6. Wang, Z.; Feng, Z.; Gao, C. Stepwise assembly of the same polyelectrolytes using host-guest interaction to obtain microcapsules with multiresponsive properties. Chem. Mater. 2008, 20, 4194-4199.

7. Pallarola, D.; von Bildering, C.; Pietrasanta, L.I.; Queralto, N.; Knoll, W.; Battaglini, F.; Azzaroni, O. Recognition-driven layer-by-layer construction of multiprotein assemblies on surfaces: A biomolecular toolkit for building up chemoresponsive bioelectrochemical interfaces. Phys. Chem. Chem. Phys. 2012, 14, 11027-11039.

8. Foster, A.; DeRosa, M.C. Development of a biocompatible layer-by-layer film systems using aptamer technology for smart materials applications. Polymers 2014, 6, 1631-1654.

9. Shiratori, S.S.; Rubner, M.F. pH-dependent thickness behavior of sequentially adsorbed layers of weak polyelectrolytes. Macromolecules 2000, 33, 4213-4219.

10. Pajor-Świerzy, A.; Kolasiňska-Sojka, M.; Warszyňski, P. The electroactive multilayer films of polyelectrolytes and Prussian blue nanoparticles and their application for $\mathrm{H}_{2} \mathrm{O}_{2}$ sensors. Colloid Polym. Sci. 2014, 292, 455-465.

11. Hoshi, T.; Akase, S.; Anzai, J. Preparation of multilayer thin films containing avidin through sugar-lectin interactions and their binding properties. Langmuir 2002, 18, 7024-7028.

12. Volodkin, D.; von Klitzing, R.; Moehwald, H. Polyelectrolyte multilayers: Toward single cell studies. Polymers 2014, 6, 1502-1527.

13. Martins, G.V.; Mano, J.F.; Alves, N.M. Nanostructured self-assembled films containing chitosan fabricated at neutral pH. Carbohydr. Polym. 2010, 80, 570-573.

14. Sato, K.; Takahashi, S.; Anzai, J. Layer-by-layer thin films and microcapsules for biosensors and controlled release. Anal. Sci. 2012, 28, 929-938.

15. Gregurec, D.; Olszyna, M.; Politakos, N.; Yate, L.; Dahne, L.; Moya, S.E. Stability of polyelectrolyte multilayers in oxidizing media: A critical issue for the development of multilayer based membranes for nanofiltration. Colloid Polym. Sci. 2015, 293, 381-388.

16. Dou, Y.; Han, J.; Wang, T.; Wei, M.; Evans, D.G.; Duan, X. Temperature-controlled electrochemical switch based on layered double hydroxide/poly( $N$-isopropylacrylamide) ultrathin films fabricated via layer-by-layer assembly. Langmuir 2012, 28, 9535-9542. 
17. Sato, K.; Takahashi, M.; Ito, M.; Abe, E.; Anzai, J. $\mathrm{H}_{2} \mathrm{O}_{2}$-induced decomposition of layer-by-layer films consisting of phenylboronic acid-bearing poly(allylamine) and poly(vinyl alcohol). Langmuir 2014, 30, 9247-9250.

18. Guo, H.; Guo, Q.; Chu, T.; Zhang, X.; Wu, Z.; Yu, D. Glucose-sensitive polyelectrolyte nanocapsules based on layer-by-layer technique for protein drug delivery. J. Mater. Sci. 2014, 25, 121-129.

19. Yoshida, K.; Hasebe, Y.; Takahashi, S.; Sato, K.; Anzai, J. Layer-by-layer deposited nano- and micro-assemblies for insulin delivery: A review. Mater. Sci. Eng. 2014, 34, 384-392.

20. Antipov, A.A.; Sukhorukov, G.B.; Leporatti, S.; Radtchenko, I.L.; Donath, E.; Möhwald, H. Polyelectrolyte multilayer capsule permeability control. Colloid Surf. A 2002, 535-541.

21. Qi, W.; Yan, X.; Fei, J.; Wang, A.; Cui, Y.; Li, J. Triggered release of insulin from glucose-sensitive enzyme multilayer shells. Biomaterials 2009, 30, 2799-2806.

22. Dam, H.H.; Caruso, F. Formation and degradation of layer-by-layer-assembled polyelectrolyte polyrotaxane capsules. Langmuir 2013, 29, 7203-7208.

23. Del Mercato, L.L.; Ferraro, M.M.; Baldassarre, F.; Mancarella, S.; Greco, V.; Rinaldi, R.; Leporatti, S. Biological applications of LBL multilayer capsules: From drug delivery to sensing. Adv. Colloid Interface Sci. 2014, 207, 139-154.

24. Marchenko, I.; Yashchenok, A.; Borodina, T.; Bukreeva, T.; Konrad, M.; Mohwald, H.; Skirtach, A. Controlled enzyme-catalyzed degradation of polymeric capsules template on $\mathrm{CaCO}_{3}$ : Influence of the number of LbL layers, conditions of degradation, and disassembly of multicompartments. J. Control. Release 2012, 162, 599-605.

25. Becker, A.L.; Johnston, A.P.R.; Caruso, F. Layer-by-layer-assembled capsules and films for therapeutic delivery. Small 2010, 6, 1836-1852.

26. Zuo, Q.; Lu, J.; Hong, A.; Zhong, D.; Xie, S.; Liu, Q.; Huang, Y.; Shi, Y.; Xue, W. Preparation and characterization of PEM-coated alginate microgels for controlled release of protein. Biomed. Mater. 2012, 7, 035012.

27. Santos, J.L.; Nouri, A.; Fernandes, T.; Rodrigues, J.; Tomás, H. Gene delivery using biodegradable polyelectrolyte microcapsules prepared through the layer-by-layer technique. Biotechnol. Prog. 2012, 28, 1088-1094.

28. Yoshida, K.; Sato, K.; Anzai, J. Layer-by-layer polyelectrolyte films containing insulin for pH-triggered release. J. Mater. Chem. 2010, 20, 1546-1552.

29. Yoshida, K.; Hashide, R.; Ishii, T.; Takahashi, S.; Sato, K.; Anzai, J. Layer-by-layer films composed of poly(allylamine) and insulin for pH-triggered release of insulin. Colloid Surf. B 2012, 91, 274-279.

30. Hashide, R.; Yoshida, K.; Kotaki, K.; Watanabe, T.; Watahiki, R.; Takahashi, S.; Sato, K.; Anzai, J. Use of anionic polysaccharides for the preparation of insulin-containing layer-by-layer films and their pH stability. Polym. Bull. 2012, 69, 229-239.

31. Hashide, R.; Yoshida, K.; Hasebe, Y.; Takahashi, S.; Sato, K.; Anzai, J. Insulin-containing layer-by-layer films deposited on poly(lactic acid) microbeads for $\mathrm{pH}$-controlled release of insulin. Colloid Surf. B 2012, 89, 242-247.

32. Li, L.; Puhl, S.; Meinel, L.; Germershaus, O. Silk fibroin layer-by-layer microcapsules for localized gene delivery. Biomaterials 2014, 35, 7929-7939.

33. Tong, W.; Gao, C.; Möhwald, H. Manipulating the properties of polyelectrolyte microcapsules by glutaraldehyde cross-linking. Chem. Mater. 2005, 17, 4610-4616. 
34. Nayak, S.R.; McShane, M.J. Encapsulation of peroxidase by polymerized acrylic acid monomers in "clean" polyelectrolyte microcapsules. J. Biomed. Nanotechnol. 2007, 3, 170-177.

35. Cui, F.; Shi, K.; Zhang, L.; Tao, A.; Kawashima, Y. Biodegradable nanoparticles loaded with insulin-phospholipid complex for oral delivery: Preparation, in vitro characterization and in vivo evaluation. J. Control. Release 2006, 114, 242-250.

36. Georgieva, R.; Moya, S.; Hin, M.; Mitlöhner, R.; Donath, E.; Kiesewetter, H.; Möhwald, H.; Baumler, H. Permeation of macromolecules into polyelectrolyte microcapsules. Biomacromolecules. 2002, 3, 517-524.

37. Mauser, T.; Déjugnat, C.; Sukhorukov, G.B. Reversible pH-dependent properties of multilayer microcapsules made of weak polyelectrolytes. Macromol. Rapid Commun. 2004, 25, 1781-1785.

38. Ye, S.; Wang, C.; Liu, X.; Tong, Z.; Ren, B.; Zeng, F. New loading process and release properties of insulin from polysaccharide microcapsules fabricated through layer-by-layer assembly. J. Control. Release 2006, 112, 79-87.

39. Richert, L.; Lavalle, P.; Payan, E.; Shu, X.Z.; Prestwich, G.D.; Stoltz, J.; Schaaf, P.; Voegel, J.; Picart, C. Layer by layer buildup of polysaccharide films: Physical chemistry and cellular adhesion aspects. Langmuir 2004, 20, 448-458.

40. Sun, B.; Jewell, C.M.; Fredin, N.J.; Lynn, D.M. Assembly of multilayered films using well-defined, end-labeled poly(acrylic acid): Influence of molecular weight on exponential growth in a synthetic weak polyelectrolyte system. Langmuir 2007, 23, 8452-8459.

(C) 2015 by the authors; licensee MDPI, Basel, Switzerland. This article is an open access article distributed under the terms and conditions of the Creative Commons Attribution license (http://creativecommons.org/licenses/by/4.0/). 